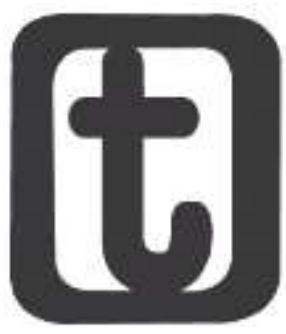

\title{
ESTÁGIO SUPERVISIONADO EM SERVIÇO SOCIAL: A INDISSOCIABILIDADE ENTRE FORMAÇÃO E TRABALHO PROFISSIONAL
}

\author{
Stage supervised in social service: the indissociability between \\ training and professional work \\ Mônica Freitas Ferri ${ }^{*}$ \\ https://orcid.org/0000-0002-2527-3844
}

\begin{abstract}
RESUMO
Componente central no processo de formação profissional o estágio supervisionado em Serviço Social é lócus privilegiado da relação teoria e prática. Compreender essa relação requer analisar o significado sócio histórico da profissão na sociedade capitalista. No contexto contemporâneo a reestruturação do Estado e suas respostas às expressões da questão social impactam diretamente o trabalho do assistente social e consequentemente o estágio supervisionado. Este artigo discute o estágio supervisionado considerando a indissociabilidade entre trabalho e formação profissional. Entende o desenvolvimento da capacitação teórico-metodológica, ético-política e técnico-operativa presente nas Diretrizes Curriculares da ABEPSS como necessárias para o exercício profissional. A revisão de literatura permite afirmar que a articulação dessas dimensões no cotidiano da formação e do trabalho do assistente social coaduna com a direção expressa no projeto ético-político da profissão e é forma de resistência e luta nos tempos atuais.
\end{abstract}

\section{PALAVRAS-CHAVE}

Estágio supervisionado. Trabalho profissional. Formação profissional.

\begin{abstract}
Central component in the process of professional training the supervised internship in Social Work is privileged locus of the relation theory and practice. Understanding this relationship requires analyzing the socio-historical significance of the profession in capitalist society. In the contemporary context the restructuring of the State and its responses to the expressions of the social question directly impact the work of the social worker and consequently the supervised stage. This article discusses the supervised internship considering the inseparability between work and professional training. It understands the development of theoretical-methodological, ethical-political and technical-operational training present in the ABEPSS Curricular Guidelines as necessary for the professional exercise. The literature review allows us to affirm that the articulation of these dimensions in the daily life of the social worker's training and work is consistent with the direction expressed in the ethical-political project of the profession and is a form of resistance and struggle in the present times
\end{abstract}

KEYWORDS: Supervised Internship. Professional Work. Professional Qualification.

\footnotetext{
* Assistente Social. Mestre em Política Social. Doutoranda do Programa de Pós-Graduação em Serviço Social da Universidade Federal do Rio de Janeiro. Professsora do Departamento de Serviço Social da Universidade Federal dos Vales do Jequitinhonha e Mucuri. (UFVJM, Teófilo Otoni, Brasil). Rua do Cruzeiro, $n^{\circ}$ 1, Jardim São Paulo, Teófilo Otoni (MG). E-mail: monicafreit@gmail.com.
}

DOI 10.22422/temporalis.2020v2on39p225-240

๑ $\mathrm{A}(\mathrm{s})$ Autora(s)/O(s) Autor(es). 2019 Acesso Aberto Esta obra está licenciada sob os termos da Licença Creative Commons Atribuição 4.0 Internacional (https://creativecommons.org/licenses/by/4.o/deed.pt_BR), que permite copiar e redistribuir o material em qualquer suporte ou formato, bem como adaptar, transformar e criar a partir deste material para qualquer fim, mesmo que comercial. O licenciante não pode revogar estes direitos desde que você respeite os termos da licença.

Temporalis, Brasília (DF), ano 20, n. 39, p. 225-240, jan./jun. 2020. | ISSN 2238-1856 


\section{INTRODUÇÃO}

D iscutir o estágio supervisionado é preocupar-se com a formação do perfil profissional crítico proposto pelas Diretrizes Curriculares da Associação Brasileira de Pesquisa em Serviço Social (ABEPSS) de 1996. Para realizar esse debate é necessário refletir sobre o trabalho e a formação profissional no contexto contemporâneo, elementos indissociáveis na capacitação do aluno-estagiário. Considera-se que o estágio é um componente central na formação profissional, mas ainda é um assunto pouco debatido pela categoria o que se reflete numa parca produção acadêmica sobre o tema.

O interesse pelo tema sempre permeou minha trajetória profissional. Na ocasião de exercício do cargo de coordenadora de estágio a demanda recorrente por parte dos supervisores de campo foi essencialmente por capacitações que tratassem da utilização dos instrumentais no âmbito da profissão, além disso era comum nos campos de estágio a repetição da célebre frase na prática a teoria é outra, e a seguinte fala direcionada aos estagiários esqueçam a teoria que agora vou lhes ensinar o que é prática. Essas constatações podem nos indicar a não compreensão de alguns profissionais acerca da necessária articulação entre as três dimensões da profissão, teórico-metodológica, técnico-operativa e ético-política no exercício profissional.

O presente artigo discute o estágio supervisionado em Serviço Social a partir da indissociabilidade do trabalho e formação profissional entendendo o estágio como central no processo de formação e lócus privilegiado da relação teoria e prática. Desenvolve a reflexão a partir de revisão de literatura sobre o tema e está dividido em três seções. A primeira aborda a unidade teoria e prática na formação e trabalho profissional. A segunda discute o Serviço Social como profissão inserida na divisão social e técnica do trabalho, a condição de trabalhador assalariado do assistente social no contexto do capitalismo contemporâneo, além de considerar a reconfiguração do Estado diante da crise, as formas de respostas às expressões da questão social e os impactos para o trabalho profissional. A terceira explana sobre a formação e trabalho profissional em Serviço Social como indissociáveis na discussão sobre estágio supervisionado, componente curricular obrigatório da formação, bem como a importância da capacitação nas três dimensões da profissão para o alcance do perfil profissional pretendido pelas Diretrizes Curriculares da ABEPSS. Acredita-se que essa discussão é fundamental para reflexão e construção de alternativas na direção da materialização de nosso projeto ético-político profissional.

\section{A UNIDADE TEORIA PRÁTICA COMO FUNDAMENTAL NO TRABALHO E FORMAÇÃO PROFISSIONAL}

De acordo com as Diretrizes Curriculares da ABEPSS (1996) a formação remete "[... ] a um conjunto de conhecimentos indissociáveis para a apreensão da gênese, das manifestações e do enfrentamento da questão social, eixo fundante da profissão e articulador dos conteúdos da formação profissional [...]" (ASSOCIAÇÃO BRASILEIRA DE PESQUISA EM SERVIÇO SOCIAL, 1996, p. 9), estruturada em Núcleos de Fundamentação da Formação Profissional ${ }^{2}$ que não são autônomos nem subsequentes, expressam níveis diferenciados de apreensão da realidade social e profissional, dando suporte à intervenção do assistente Social.

2 a) Núcleo de Fundamentos Teórico-Metodológicos da Vida Social, b) Núcleo de Fundamentos da Formação Sócio-Histórica da Sociedade Brasileira e c) Núcleo de Fundamentos do Trabalho Profissional.

Temporalis, Brasília (DF), ano 20, n. 39, p. 225-240, jan./jun. 2020. | ISSN 2238-1856 


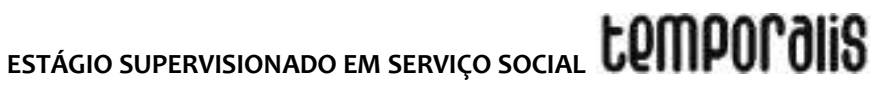

Assim, observa-se que teoria e prática são indissociáveis e o profissional que não tem uma postura investigativa em seu cotidiano corre o risco de reproduzir ações pragmáticas, já que de acordo com Guerra (2013) na própria trajetória da profissão a mesma se especializa em responder demandas que exigem solução imediata de problemas em especial aqueles que tensionam e ameaçam o ordenamento social.

A preocupação com as questões da prática são pertinentes à profissão, tendo em vista que no contexto da divisão sócio-técnica do trabalho, o assistente social é investido como um dos agentes executores das políticas sociais e o lugar que ocupa nesta divisão circunscrevese no marco das ações executivas. A profissão está alocada primordialmente na execução programática, e com uma intervenção avaliada por suas resultantes empíricas (NETTO, 2011).

Em seu livro Na prática a teoria é outra Santos (2010) ressalta que tem sido comum duas afirmativas no Serviço Social: 1) "Na prática a teoria é outra" e 2) "o movimento de intenção de ruptura ${ }^{3}$ no Serviço Social não se viu acompanhar de um arsenal de instrumentos e técnicas próprios".

De acordo com Netto (2008) a perspectiva intenção de ruptura na expressão dos segmentos mais avançados da categoria profissional conserva seus traços dominantes de oposição ao tradicionalismo profissional, amplia as referências teóricas e ideoculturais do Serviço Social, qualificando-a no debate acadêmico e político. Contudo, observa-se um hiato entre a intenção de romper com o passado conservador da profissão e os indicativos prático-profissionais para consuma-la.

De acordo com Silva (2011) no início do movimento do esforço de ruptura havia uma apropriação problemática com o marxismo, com uma recorrência acentuada a intérpretes de Marx, no entanto, no final da década de 1980 e início dos anos 1990 a aproximação direta com Marx e marxistas contemporâneos é indiscutível, pelo menos no âmbito da academia, especialmente nos cursos de pós-graduação. Contudo, no que se refere a graduação essa aproximação permanece marcada por debilidades e tensões, e quando se considera o conjunto da categoria essa distância é ainda maior demonstrando a base teórico-conceitual que fundamenta o Projeto de Ruptura ${ }^{4}$ é de domínio restrito no âmbito da categoria profissional com implicações que dificultam a implementação do referido projeto ${ }^{5}$.

Segundo Santos (2010) existe uma lacuna quanto à questão dos instrumentos e técnicas dos assistentes sociais no Brasil que para ela advém de uma incorporação equivocada e

\footnotetext{
3 Netto (2008) afirma que erodida a base do Serviço Social tradicional a reflexão profissional quer cronológica ou teoricamente se desenvolveu em três direções constitutivas do processo de renovação. São elas: a perspectiva modernizadora, a reatualização do conservadorismo e a intenção de ruptura. Esta última busca romper com os suportes teóricos, metodológicos, e ideológicos próprios do Serviço Social tradicional baseados na tradição positivista e no reformismo conservador, recorrendo a tradição marxista.

4 Desde finais da década de setenta o Serviço Social brasileiro vem construindo um projeto ético-político profissional comprometido com os interesses das classes trabalhadoras. Este projeto avançou nos anos 1980, consolidou-se nos anos 1990 e ainda está em construção (REIS, 2000).

50 projeto ético-político tem em seu núcleo o reconhecimento da liberdade como valor central - a liberdade concebida historicamente como possibilidade de escolher entre alternativas concretas; daí um compromisso com a autonomia, a emancipação e a plena expansão dos indivíduos sociais. Consequentemente, o projeto profissional vincula-se a projeto societário que propõe a construção de uma nova ordem social, sem dominação e/ou exploração de classe, etnia e gênero (NETTO, 1999, p. 104-105).
}

Temporalis, Brasília (DF), ano 20, n. 39, p. 225-240, jan./jun. 2020. | ISSN 2238-1856 
não satisfatória da relação teoria e prática na concepção do materialismo históricodialético. Para a autora, embora a profissão tenha avançado quando enfatizou a unidade das dimensões da prática interventiva em uma relação dialética, a formação profissional trata a unidade sem levar em conta suas especificidades. A ideia de que na prática a teoria é outra revela uma incompreensão de teoria e prática que rebatem na não compreensão de prática profissional. "A ausência de entendimento sobre prática profissional aparece, muitas vezes, associando-se a prática profissional como práxis social e práxis revolucionária, assim como a reduzindo a aplicação de instrumentos e técnicas" (SANTOS, 2010, p. 14).

A partir do materialismo dialético Santos (2010) define teoria como a apreensão das determinações que constituem o concreto, como forma de atingir pelo pensamento a totalidade, a expressão do universal, ao mesmo tempo que culmina no singular e no universal; e a prática como o processo de constituição desse concreto, constitutiva e constituinte das determinações do objeto, geradora de produtos que constituem o mundo real. A teoria é um instrumento de análise do real, logo tem na prática seu fundamento. Assim, “[... ] na prática a teoria só pode ser a mesma, uma vez que ela é o lugar onde o pensamento se põe" (SANTOS, 2010, p. 27). O âmbito da prática é o da efetividade da ação sobre o mundo, que tem por resultado a transformação real desse mundo e o âmbito da teoria é o da produção de conhecimentos, da possibilidade, de desencadeador de finalidades ou resultados ideais para ação (SANTOS, 2010).

De acordo com Santos (2010) a competência teórica é indispensável à formação profissional, mas sozinha não habilita para a intervenção. Os instrumentos utilizados na operacionalização da intervenção profissional não podem ser aferidos diretamente de uma dada direção teórica, pois possuem uma relação quase imediata com a prática. A prática profissional é uma expressão da práxis social ${ }^{6}$ e tem por características ser socialmente determinada e produto de seus agentes profissionais, é histórica, mutável e exige permanentes redefinições frente as transformações societárias e as mudanças nas expressões da "questão social".

Prática profissional não pode se confundir com prática política, possui caráter político, podendo contribuir para manutenção do status quo ou para transformação da realidade. Pode ter como horizonte o apoio ou a identificação com a práxis revolucionária, mas não é responsável por ela. A ação profissional está circunscrita na divisão social e técnica do trabalho, logo seu nível de intervenção não é o de rompimento com essa ordem, mas pode ser de intenção de ruptura, a medida que contribui para o fortalecimento de uma consciência revolucionária e para uma materialidade de ampliação da cidadania (SANTOS, 2010).

A questão da relação entre teoria e prática é um problema que pertence à relação entre mercado de trabalho e formação profissional. Como as necessidades do mercado são dinâmicas, esse dinamismo não é correspondido imediatamente pela formação, o conhecimento é pos-festum, assim a formação jamais corresponderá totalmente às demandas do mercado. Se a universidade se fecha às necessidades do mercado perde sua capacidade de crítica diante das necessidades, que veladas na sociedade precisam ser

$6[\ldots]$ é um tipo de práxis cujo objeto de atividade prática é a sociedade ou os homens reais; o objetivo é a transformação do mundo social, e a atividade toma por objeto não um indivíduo isolado, mas grupos ou classes sociais, inclusive a sociedade inteira (VASZQUEZ apud SANTOS, 2010, p. 41).

Temporalis, Brasília (DF), ano 20, n. 39, p. 225-240, jan./jun. 2020. | ISSN 2238-1856 
respondidas, e esse desvendamento só é possível a partir de uma formação competente que privilegie conhecimentos teóricos rigorosos e críticos, que conheça o mercado de trabalho, mas não se limita a ele (SANTOS, 2010).

Para Santos (2010) é necessária a discussão do ensino dos instrumentos e técnicas pelo coletivo de profissionais (de campo, supervisores de estágio, pesquisadores), instituições e órgãos responsáveis pela formação, pensar sobre a instrumentalidade da profissão e seus instrumentos e técnicas, pois "[...] ter maior habilidade no manuseio dos instrumentos pode diminuir as angústias dos profissionais, contribuindo para que se detenham no aprofundamento das reais dificuldades inerentes à sua intervenção" (SANTOS, 2010, p. 97). Para a autora a intervenção de qualidade requer mediações que se fundamentam e se sustentam num referencial teórico-metodológico, ético-político e técnico operativo.

Profissionais que não realizem a reflexão teórica em seu cotidiano fatalmente reproduzirão acriticamente o padrão moralizador das políticas sociais, culpabilizando os sujeitos por sua condição. Ou ainda, muito provavelmente, cairão no fatalismo ou messianismo, por um lado, superestimando a força e a lógica do comando do capital no processo de (re)produção, desconsiderando a possibilidade dos profissionais atribuírem direção às suas atividades, ou por outro lado, superestimar a vontade política do coletivo profissional, correndo o risco de diluir a profissionalização na militância estritamente, desconsiderando os determinantes históricos-estruturais objetivos (IAMAMOTO, 2008).

Para isso que isso não ocorra é necessário compreender a dupla dimensão do trabalho profissional enquanto trabalho concreto e abstrato no contexto do capitalismo contemporâneo, as reconfigurações do Estado e das políticas sociais neste cenário, e os impactos para o trabalho profissional. Elucidar essas questões são de extrema importância, pois refratam nos campos de estágio, espaços sócio-ocupacionais dos assistentes sociais é o que será abordado na próxima seção.

\section{O SERVIÇO SOCIAL NA DIVISÃO SOCIAL E TÉCNICA DO TRABALHO: DESAFIOS CONTEMPORÂNEOS}

O Serviço Social é um tipo de especialização do trabalho coletivo dentro da divisão social e técnica do trabalho. Se situa no processo de reprodução das relações sociais e se gesta e desenvolve como profissão reconhecida na divisão do trabalho a partir do desenvolvimento capitalista industrial e da expansão urbana. Esse cenário traz a constituição de novas classes sociais (burguesia e proletariado) e alterações na composição dos grupos e frações de classe que compartilham o poder do Estado. Nesse contexto, emerge sob novas formas a "questão social" (IAMAMOTO, 2001).

A partir das lutas de classe o Estado passa a intervir diretamente nas relações entre empresariado e classe trabalhadora através da criação de legislações de regulação do mercado de trabalho, legislações sociais e trabalhistas. O Estado implementa serviços sociais enfrentando de nova forma a questão social, com o objetivo de garantir os níveis de produtividade do trabalho exigidos no estágio de desenvolvimento do capital (IAMAMOTO, 2001). 
A profissão afirma-se no Brasil tendo como seu maior empregador o Estado, vinculando-se também a organizações privadas, como profissional assalariado. Embora regulamentado como profissão liberal, o Serviço Social no Brasil não é necessariamente um profissional autônomo, pois não dispõe das condições materiais e técnicas para seu trabalho e controle sobre o mesmo. Embora, certos traços marquem uma prática liberal, como sua deontologia, o caráter não rotineiro da intervenção, a relação singular no contato com os usuários e a possibilidade de seu exercício independente, embora sejam poucas as experiências no país (IAMAMOTO, 2001). Assim, destaca a autora "O trabalho do assistente social se insere numa relação de compra e venda de mercadorias onde sua força de trabalho é mercantilizada" (IAMAMOTO, 2001, p. 85).

De acordo com lamamoto (2001) o Serviço Social não é uma profissão que se inscreve predominantemente entre as atividades que estejam diretamente vinculadas à produção de produtos e de valor7, contudo, isto não significa que esteja alijada da produção social em sentido amplo. Atuando no processo de reprodução da força de trabalho através da prestação de serviços sociais, o Serviço Social enquanto profissão, participa da tarefa da implementação das condições necessárias ao processo de reprodução em seu conjunto, tendo em vista que contribui diretamente para a reprodução da força de trabalho em ação (trabalhador) que é a fonte da produção de novos valores.

O trabalho do assistente social social atende a necessidades sociais, daí seu caráter útil, mas só pode atender às necessidades sociais se for igualado a qualquer outro trabalho abstrato (mero coágulo de tempo de trabalho social médio) o que possibilita que o trabalho privado adquira um caráter social. Sendo proprietário de uma força de trabalho especializada esta só pode entrar em ação a medida que se alia aos meios necessários à sua realização, que majoritariamente se encontram monopolizados pelos empregadores, recursos materiais, humanos, necessários à realização do trabalho concreto. Existe uma ingerência de empregadores, na definição do trabalho profissional, pois este ingressa nas instituições como parte de um coletivo de trabalhadores que implementa ações institucionais, cujo resultado final é fruto de um trabalho combinado e cooperativo. A relação que o assistente social estabelece com o objeto de seu trabalho, as múltiplas expressões da questão social, depende do recorte das políticas definidas pelos organismos empregadores, que estabelecem demandas e prioridades a serem atendidas (IAMAMOTO, 2008).

Todos esses elementos estão na contramão da integral autonomia do trabalho do assistente social. Que na relação de compra e venda de sua mercadoria força de trabalho entrega ao empregador seu valor de uso, que é o direito que o empregador tem de consumir durante um tempo determinado por uma relação contratual sua força de trabalho. O trabalhador não tem o poder de direcionar suas ações livremente, estabelecer suas prioridades, acessar todos os recursos. Contudo, o assistente social tem sua autonomia relativa legitimada pela formação universitária e pelo aparato legal organizativo que regulam o exercício de uma profissão liberal na sociedade (expressos na legislação profissional e nos Conselhos Profissionais). Esta autonomia está condicionada pelas lutas de classes que alargam ou retraem as bases que sustentam a direção social estratégica do

7 Para Marx (2004) “[... ] é produtivo o trabalho que valoriza diretamente o capital, o que produz mais-valia [...]” (MARX, 2004, p. 70). É improdutivo aquele trabalho que não produz valia, geralmente àqueles realizados na esfera dos serviços públicos.

Temporalis, Brasília (DF), ano 20, n. 39, p. 225-240, jan./jun. 2020. | ISSN 2238-1856 
projeto ético profissional da categoria no atendimento dos interesses das classes trabalhadores em seus espaços sócio-ocupacionais de trabalho (IAMAMOTO, 2008).

Feitas essas considerações, pensar o trabalho do assistente social no contexto contemporâneo requer compreender algumas alterações no âmbito do capitalismo mundial a partir da década de 1970 que provocaram mudanças significativas nas formas de responder as expressões da questão social via políticas sociais, mediação fundamental do trabalho profissional.

A partir da década de 1970 o capitalismo mundial entra numa crise clássica de superprodução, onde a universalização da revolução tecnológica, o pleno emprego no período expansivo, o poder de barganha dos trabalhadores dos setores monopolistas provocaram a erosão inexorável da taxa média de lucros e a ampliação das dificuldades no âmbito do consumo (BEHRING, 2002). Esta crise redesenhou o capitalismo contemporâneo, o que Harvey (2010) denominou de passagem do fordismo à acumulação flexível, que se apoia na flexibilidade dos processos de trabalho, dos mercados de trabalho, dos produtos e padrões de consumo.

Nesse contexto tem-se o redimensionamento do Estado no que se refere a cobertura dos direitos sociais, especialmente nos países em que vigorou o Welfare State. Visando reduzir os custos do capital na reprodução da força de trabalho, há um corte nos direitos sociais passando a vigorar o Estado mínimo no que se tange as coberturas sociais públicas (NETTO, 2013).

Caracterizam esse processo a transferência para a sociedade civil de ações antes praticadas pelo Estado, surge o novo assistencialismo ou nova filantropia, que se traduzem nas parcerias público-privadas para confrontar-se com a pobreza absoluta. As políticas de renda mínima são o carro chefe das ações do Estado atendendo às recomendações dos organismos internacionais para erradicação da extrema pobreza (NETTO, 2013).

No Brasil a partir da crise econômica na década de 1970, o governo militar implantado em 1964 começa a perder sua legitimidade e há uma reativação dos movimentos sociais, de base operária e popular, constituindo uma vasta teia de organizações que passaram a dinamizar processos de mobilização para conquista, defesa e ampliação dos direitos civis, políticos e sociais que se referiam à trabalho, moradia, saúde, educação, entre outros. Surgiram neste cenário movimentos que trouxeram à tona debates como o da discriminação de gênero, raça, meio ambiente, violência e direitos humanos, estes foram chamados os Novos Movimentos Sociais ${ }^{8}$. Destaca-se também o movimento sindical renovado protagonizado por grupos operários em São Paulo (greves entre 1978 e 1980) (DURIGUETTO, 2007).

A interação do associativismo de base com o movimento sindical e partidos políticos, que acontece essencialmente na década de 1980, trouxe grandes avanços e ganhos políticos que se expressam na Constituição Federal de 1988. Entretanto, o grande capital e seus representantes políticos conseguiram bloquear no plano do Estado a sua reforma democrática e por em curso, através do governo de Fernando Collor de Melo, a contra-

8 Sobre os principais autores do debate teórico deste tema no Brasil consultar Braz (2012).

Temporalis, Brasília (DF), ano 20, n. 39, p. 225-240, jan./jun. 2020. | ISSN 2238-1856 
reforma, um movimento de reestruturação já iniciado nos países centrais há mais de uma década (NETTO, 2004).

O Brasil promulga a constituição cidadã num momento histórico em que a maior parte dos países centrais, regidos pelo Estado de bem-estar social, passa a negar os princípios socialdemocratas de regulação econômico-social, na tentativa de restabelecer os ganhos capitalistas frente à crise mundial. A saída apontada para a crise consistia na adoção de políticas neoliberais de redução do papel do Estado nas políticas sociais e econômicas. As mudanças propostas produzem impacto imediato nas economias latino-americanas e a adoção de políticas de cunho liberal passa a ser condição para manutenção das relações econômicas internacionais (DRAIBE, 1993).

Neste contexto a tendência geral do capitalismo contemporâneo é de redução de direitos, sob o argumento da crise fiscal, transformando-se as políticas sociais em ações pontuais e compensatórias. A privatização, focalização e descentralização são o trinômio que se constitui no repasse de responsabilidades para entes da federação ou para instituições privadas e novas modalidades jurídico-institucionais que configuram o setor público nãoestatal (BEHRING, 2008).

Diante desta conjuntura recessiva, os assistentes sociais sofrem com a precarização do trabalho que se expressa na redução do trabalho formal, no processo de terceirização, de subcontratação de serviços individuais dos assistentes sociais por parte de empresas de serviços e assessoria, de cooperativas de trabalhadores, de prestação de serviços para governos e organizações não governamentais, através do trabalho autônomo, temporário, por projeto, tarefa, devido a as novas formas de gestão das políticas sociais. A tríade flexibilização/precarização/terceirização traz impactos para a profissão já que com a precarização dos contratos de trabalho convivem no mesmo espaço ocupacional profissionais com diferentes formas de contrato e níveis salariais, o que dificulta até mesmo sua organização e luta coletiva. Isso impacta na qualidade dos serviços prestados aos usuários e na descontinuidade dos serviços (RAICHELIS, 2011).

Outras situações aliadas às condições de trabalho se referem aos baixos níveis de sindicalização, a inobservância de boa parte dos empregadores quanto a lei das 30 horas (Lei Federal 12317/2010), além de situações de insalubridade e de assédio moral (COFICRESS/RJ, 2014 apud IAMAMOTO, 2017). A inobservância da Resolução do CFESS n. 493/2006, que dispõe sobre as condições técnicas e éticas para o exercício profissional do assistente social, também é uma realidade. Não é garantida a guarda de material sigiloso; salas adequadas, direito ao sigilo profissional do cidadão atendido pelo assistente social no que se refere à sua individualidade, no trabalho interdisciplinar, além da ausência de recursos materiais básicos para a realização do trabalho profissional (IAMAMOTO, 2017).

As alterações nas configurações das políticas sociais diante da crise, que se traduzem em respostas seletivas, focalizadas e fragmentadas às expressões da questões aliadas à precarização das condições de trabalho profissional tem colocado desafios a materialização de nosso projeto profissional tanto no que se refere a formação e ao exercício profissional. A lógica conservadora das políticas sociais, orientadas pela perspectiva neoliberal, requer um profissional acrítico que responda às demandas emergentes do cotidiano. Sendo este o espaço privilegiado da atuação profissional, isto pode comprometer a formação do perfil profissional crítico posto pelas Diretrizes 
Curriculares da ABEPSS, tendo em vista que o estágio ocorre a partir da inserção do aluno no espaço sócio-ocupacional com o objetivo de capacita-lo para o exercício do trabalho profissional. Essas questões serão tratadas na próxima seção.

\title{
A FORMAÇÃO ACADÊMICO-PROFISSIONAL, TRABALHO E ESTÁGIO EM SERVIÇO SOCIAL
}

As Diretrizes Curriculares da ABEPSS definem o perfil do bacharel em Serviço Social como

\begin{abstract}
Profissional que atua nas expressões da questão social, formulando e implementando propostas para seu enfrentamento, por meio de políticas sociais públicas, empresariais, de organizações da sociedade civil e movimentos sociais. Profissional dotado de formação intelectual e cultural generalista crítica, competente em sua área de desempenho, com capacidade de inserção criativa e propositiva, no conjunto das relações sociais e no mercado de trabalho. Profissional comprometido com os valores e princípios norteadores do Código de Ética do Assistente Social (ASSOCIAÇÃO BRASILEIRA DE ENSINO E PESQUISA EM SERVIÇO SOCIAL, 1996, p. 27).
\end{abstract}

A formação profissional constitui-se de uma totalidade de conhecimentos que estão expressos nos seus três núcleos de fundamentação que congregam conteúdos como eixos articuladores da formação profissional pretendida, e desdobram-se em áreas de conhecimento. "Esta articulação favorece uma nova forma de realização das mediações aqui entendida como a relação teoria-prática - que deve permear toda a formação profissional, articulando ensino-pesquisa-extensão" (ASSOCIAÇÃO BRASILEIRA DE ENSINO E PESQUISA EM SERVIÇO SOCIAL, 1996, p. 8).

Contudo, de acordo com lamamoto (2017) a formação desse perfil profissional encontrase comprometido na atualidade.

Na formação acadêmico-profissional em Serviço Social, as universidades públicas e as PUCs congregam os cursos de excelência na área implementando as diretrizes curriculares propostas pela Abepss. Entretanto, predomina o ensino privado em instituições não universitárias, o que compromete a integração entre ensino, pesquisa e extensão. Isso ocorre em um contexto no qual o ensino superior passa a ser visto como 'negócio educativo', e não como direito social (IAMAMOTO, 2017, p. 32).

Segundo lamamoto (2017) em agosto de 2012 existiam 567 cursos de graduação em Serviço Social autorizados, sendo 518 privados (91,4\%) e 49, públicos (8,6\%). "Os 230 cursos à distância são exclusivamente privados e correspondem a $44,4 \%$ do conjunto dos cursos privados, enquanto os presenciais somam 288 , ou seja, $55,6 \%$ dos cursos privados" (IAMAMOTO, 2017, p. 20-21).

A expansão acelerada do ensino superior privado, particularmente na EAD, tem implicações concretas na formação, aligeiramento no trato da teoria e ênfase no treinamento. A perda de "[... ] qualidade da formação universitária facilitam a submissão dos profissionais às demandas e 'normas do mercado', tendentes a um processo de politização à direita da categoria” (IAMAMOTO, 2017, p. 33).

Essa realidade de massificação do ensino já impacta na formação profissional, sobretudo dos/as novos/as assistentes sociais, formados nessa lógica privatista e mercantil, que inclui a controversa modalidade do EaD. Como já denunciado em

Temporalis, Brasília (DF), ano 20, n. 39, p. 225-240, jan./jun. 2020. | ISSN 2238-1856 
diversos documentos das Organizações dos Assistentes Sociais, a formação nessa modalidade fere os princípios e orientações defendidos pelas Diretrizes Curriculares da ABEPSS e vem trazendo enormes desafios para os enfrentamentos políticos e éticos da categoria na defesa do projeto profissional (RAMOS; ABREU, 2016, p. 83)

Diversas denúncias presentes no processo de formação que chegam aos CRESS mostram que o estágio supervisionado tem sido o objeto mais impactado com a precarização e proliferação desenfreada do mercado através dos cursos de graduação presencial e a distância. Esses cursos não se comprometem com uma formação que articula ensino, pesquisa e extensão, muito menos pautam-se por um perfil crítico e propositivo do serviço social contemporâneo. Além disso, não se pode perder de vista o tensionamento entre o projeto profissional e as demandas imediatas do mercado, é importante considerar a condição de assalariamento do assistente social e a retração de recursos institucionais para acionar a defesa de direitos e dos meios de acessá-los (RAMOS; ABREU, 2016).

O estágio supervisionado curricular, nas modalidades obrigatório e nãoobrigatório, é um processo didático-pedagógico que se consubstancia pela 'indissociabilidade entre estágio e supervisão acadêmica e profissional' (ABESSCEDEPSS, 1997, p. 62), um dos princípios das diretrizes curriculares para o curso de Serviço Social. Caracteriza-se pela atividade teórico-prática, efetivada por meio da inserção do(a) estudante nos espaços sócio-institucionais nos quais trabalham os(as) assistentes sociais, capacitando-o(a) nas dimensões teórico-metodológica, ético-política e técnico-operativa para o exercício profissional (ASSOCIAÇÃO BRSILEIRA DE ENSINO E PESQUISA EM SERVIÇO SOCIAL, 2010, p. 14).

Entende-se que o estágio é o espaço privilegiado da formação profissional e deve ocupar lugar de destaque na formação por ter a profissão uma natureza interventiva, tem as condições de propiciar a síntese entre o trabalho e a formação profissional, mas as condições de realização da supervisão dependem das condições de realização do trabalho profissional e das condições sob as quais a formação se realiza que a depender do grau de deterioração podem comprometer a realização do estágio supervisionado (GUERRA, 2016).

O estágio é o lócus privilegiado do conhecimento da realidade, do desenvolvimento do perfil crítico do estagiário desde que este desenvolva, a partir de técnicas de análise de conjuntura e institucional, uma reflexão que ultrapasse a aparência dos fatos e busque a essência dos processos. É no estágio supervisionado que o estudante mobiliza os conhecimentos adquiridos na academia para compreensão da realidade em que está inserido, podendo perceber como a crise atual do capital expressa-se no contexto sóciopolítico da instituição, as alterações que a Reforma Gerencial do Estado operou nas estruturas e dinâmicas institucionais, a regência das instituições por contratos de gestão e programas direcionados por metas quantitativas, supostamente em nome da eficiência e eficácia. Além disso, é possível aos estudantes captar os significado da política social, o antagonismo de interesses e as lutas de classe como elemento constitutivo das políticas sociais (GUERRA, 2016).

O estágio permite que o estudante vivencie e capture o significado da profissão na rede de relações sociais, o lugar que ela ocupa na divisão sociotécnica do trabalho, sua funcionalidade ao padrão de sociabilidade dominante, o antagonismo dos interesses e demandas que se põe à profissão, sua instrumentalidade como condição de alcance de seus objetivos, o que realmente 


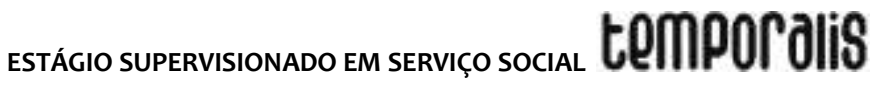

é e faz; a intencionalidade dos meios mobilizados e sua adequação às finalidades (GUERRA, 2016, p. 111).

É expressão mais desenvolvida da unidade entre teoria e prática, propicia a vivência de situações profissionais que desafiam os estudantes em seus valores e desvalores (preconceitos) próprios da moralidade burguesa, constatá-los e reve-los. Assim, o estágio permite que o estudante desenvolva um espírito crítico que detecte as pressões para uma rápida adesão e adaptação à racionalidade instrumental e às condições de flexibilização operadas nos espaços de trabalho no que se refere às formas de contratação dos profissionais e direitos garantidos. Desse modo, o estágio congrega uma dupla dimensão a do conhecimento e da ação, onde juntamente com o supervisor o estagiário deve aprender a apreender e essa aprendizagem está relacionada ao ser, fazer, conhecer, conviver, pensar, que impõe aptidões, habilidades, atitudes, posturas, compromissos, comportamentos e posturas (GUERRA, 2016).

Considerando que a profissão é interventiva, Guerra (2016) aponta que é necessário abordar com cuidado o potencial da dimensão técnico-operativa, pois ela é fundamental no perfil profissional do formando. A capacitação técnico-operativa

[...] deve permitir a formação de um perfil profissional que detém o domínio do instrumental técnico e de pesquisa com vistas a desenvolver a capacidade argumentativa e de negociação, que também detém conhecimento e domínio das técnicas e diretrizes de planejamento, que saiba propor, organizar e administrar serviços sociais; que seja capaz de organizar e viabilizar canais de participação do usuário nas decisões institucionais (GUERRA, 2016, p. 115).

Compreende ainda o ensino e a prática de elaborar projetos de intervenção, identificar e debater indicadores sociais, avaliar o impacto dos programas institucionais na vida dos usuários dos serviços, capacidade de realizar visitas e perícias técnicas, estudos socioeconômicos e a elaborar laudos e pareceres; além de desenvolver processos de avaliação monitoramento nos vários níveis de intervenção, criar formas de registro e documentação capazes de permitir a sistematização da intervenção profissional, avaliar e planejar sistematicamente as atividades, ultrapassando rotinas com vistas à produção de conhecimento crítico e dar visibilidade e continuidade ao trabalho do assistente social (GUERRA, 2016).

De acordo com Guerra (2016) é necessário investir na qualificação dos supervisores acadêmicos e de campo e qualificação do processo de supervisão, pois deve-se buscar a capacitação necessária para o exercício dessa atribuição privativa. O supervisor de campo nem sempre possui a real capacitação e qualificação para assumir esta atribuição privativa. Pode ocorrer em alguns casos a substituição do profissional pelo estagiário, devido às demandas imediatas dos campos, caracterizando exercício ilegal da profissão entre outras situações.

O supervisor acadêmico "[...] tem a atribuição precípua de trabalhar as mediações que conectam os fundamentos históricos, teóricos, metodológicos, éticos, políticos com as experiências que se realizam no campo de estágio [...] (GUERRA, 2016, p. 120). Contudo, nem sempre o supervisor acadêmico tem condições objetivas para isso aponta que o processo de supervisão muitas vezes se caracteriza como um trabalho a mais tanto para $o$ supervisor acadêmico como para o supervisor de campo e ambos nem sempre estão

Temporalis, Brasília (DF), ano 20, n. 39, p. 225-240, jan./jun. 2020. | ISSN 2238-1856 
cientes da concepção de estágio das diretrizes ou mesmo coadunam com que está posto na Política Nacional de Estágio (GUERRA, 2016).

Nesse sentido, considerando a importância do estágio no processo de formação profissional, é preciso investir no processo de qualificação permanente dos supervisores. $\mathrm{Na}$ atribuição privativa da supervisão, a dimensão formativa se situa no centro da constituição do exercício profissional. "A formação contínua, entendida como sistemática e permanente, compreende a relação entre graduação e pós graduação, compreende a necessária especialização na área de intervenção e uma permanente atualização" (GUERRA, 2016, p. 121, grifos da autora).

Considerando a dimensão ético-política Forti e Coelho (2015) abordam que uma das questões postas hoje são as dificuldades de materialização das diretrizes do projeto éticopolítico profissional, diante da realidade do trabalho profissional no campo das políticas sociais, na sociedade capitalista da era neoliberal, afetando diretamente os espaços sócioocupacionais.

Nas três últimas décadas o Serviço Social rumou na direção dos interesses dos trabalhadores e assumiu compromissos progressistas e democráticos, todavia essa direção social só poderá ser avaliada como hegemônica se for possível mostrar repercussão prática e teórica. A materialização do projeto ético-político profissional exige nos colocarmos em prol de valores que confrontem a alienação, a desigualdade social e a banalização da vida fundamentada em conhecimentos teórico-práticos compatíveis com esta finalidade (FORTI; COELHO, 2015).

As autoras ressaltam ainda, que a objetivação de valores democráticos exige que se coloque a dimensão ético-política no centro do exercício profissional, esta deve dar sentido à ação profissional, dirigindo seu comprometimento aos interesses de determinada classe social. Na atualidade a classe dominante está na ofensiva e as lutas e enfrentamentos estão no chão das fábricas, na luta cotidiana por direitos, pelo controle social do fundo público. Assim, "[...] a dimensão instrumental-operativa da profissão não pode ser apartada das dimensões teórico-metodológica e ético-política" (FORTI; COELHO, 2015, p. 35). Desse modo, afirmam que fortalecer e defender o projeto ético-político do Serviço Social impõe a luta contra a superexploração da força de trabalho em geral e a articulação e inserção nas lutas sociais do tempo presente.

Guerra (2015) defende a viabilidade e atualidade do projeto profissional do Serviço Social apesar das ameaças e desafios atuais, pois ele resgata os pilares do projeto da modernidade e os valores universalistas, além de fundamentar-se em valores civilizatórios construídos nas lutas históricas da classe trabalhadora e em identidades coletivas rejeitando os valores da sociedade burguesa, faz a crítica aos preconceitos produzidos por esta sociedade. Além da luta por direitos a autora salienta que o horizonte do projeto profissional é a construção de uma nova ordem societária, sem dominação, exploração de classe, etnia e gênero e para é isso é necessário que tenhamos como substância do projeto a revolução. Para ela não basta fazer a crítica ontológica da sociedade é preciso revolucioná-la.

Conforme nos aponta Santos (2010) é preciso ter clareza do significado sócio-histórico da profissão, nossa prática não pode ser revolucionária, o que podemos, é enfrentar às 
expressões da questão social dentro da ordem vigente, visando a sua superação. A ação do assistente social é circunscrita na divisão social e técnica do trabalho, de modo que seu nível de intervenção não é o rompimento com essa ordem ainda que o Serviço Social tenha este como seu objetivo último.

[... ] a prática interventiva do Serviço Social, apesar de não fazer a revolução, de não se tratar de uma transformação radical ao assumir seu compromisso com uma ação profissional voltada para a defesa de direitos sociais, equidade e justiça social, comprometida com a luta pela consolidação da cidadania e da democracia, que incentive a organização da população - em consonância com o projeto éticopolítico profissional -, pode contribuir para o fortalecimento de uma consciência revolucionária e de uma materialidade de ampliação da cidadania que, em última instância, colide com a lógica do Capital (SANTOS, 2010, p. 49).

Compreender o significado da profissão na sociedade capitalista e a relação teoria e prática é fundamental para garantir uma formação e um exercício profissional que não reproduzam equívocos e posturas fatalistas ou messiânicos quanto às possibilidades de materialização de nosso projeto ético-político no cotidiano. A tarefa que se coloca para todos nós assistentes sociais é acionar as dimensões teórico-metodológica, técnicooperativa e ético-política no cotidiano da formação e trabalho profissional.

\section{CONSIDERAÇÕES FINAIS}

Apesar do estágio ter centralidade na formação profissional observa-se que ainda é muito restrito o debate sobre o tema no interior da categoria. Muitos são os desafios no âmbito da realização desse componente curricular da formação e enfrentá-los certamente passa pela formação de nossa categoria profissional, pelas lutas contra a superexploração dos trabalhadores em geral, por melhores condições de trabalho para a própria categoria e pela defesa das políticas sociais como direitos, sem perder de vista o horizonte de nosso projeto ético-político que é a construção de uma nova ordem societária.

No âmbito da formação profissional é necessário potencializar os cursos de capacitação de supervisores de estágio em parceria com as instituições concedentes tentando ao máximo garantir a participação dos supervisores de campo. Investir na abertura de Programas PósGraduação lato-sensu e stricto-sensu para os supervisores de estágio faz-se urgente e necessário, tendo em vista que diante do quadro de expansão do ensino privado e à distância e da não garantia de uma formação que garanta o perfil profissional crítico de acordo com as Diretrizes Curriculares da ABEPSS como nos apontou lamamoto (2017), capacitar os profissionais é investir na consolidação do projeto profissional do Serviço Social e sinal de resistência. Esses Programas Pós-Graduação poderão ser criados em parcerias entre as Unidades de Formação Acadêmicas (UFAS) e as entidades representativas da categoria fortalecendo a direção social estratégica da profissão. As estratégias de consolidar uma formação profissional de qualidade com base na teoria social crítica pode contribuir para se superem e/ou diminuam os equívocos em relação a suposta dicotomia teoria e prática que interferem na atuação profissional e na formação do estagiário.

No que se refere as condições de trabalho as estratégias da categoria existem e precisam ser fortalecidas, como a articulação com a luta geral dos trabalhadores contra a retirada de direitos, no âmbito da própria categoria a luta por um piso salarial, o observatório da lei

Temporalis, Brasília (DF), ano 20, n. 39, p. 225-240, jan./jun. 2020. | ISSN 2238-1856 
das 30 horas, além das constantes lutas em defesa das políticas sociais. A criação e fortalecimento dos Núcleos de Assistentes Sociais vinculados aos CRESS em regiões distantes dos grandes centros, ou onde não há seccionais, a criação e fortalecimento de Fórum de Trabalhadores das Políticas Públicas e das diversas áreas em que atuam os assistentes sociais são também importantes espaços de articulação da categoria contra a precarização das condições de trabalho, estas também são formas de contribuir para consolidação de nosso projeto profissional.

\section{REFERENCIAS}

ASSOCIAÇÃO BRASILEIRA DE ENSINO E PESQUISA EM SERVIÇO SOCIAL (ABEPSS). Política Nacional de Estágio da Associação Brasileira de Ensino e Pesquisa em Serviço Social: Abepss. Brasília (DF), 2010.

ASSOCIAÇÃO BRASILEIRA DE ENSINO E PESQUISA EM SERVIÇO SOCIAL (ABEPSS). Lei de Diretrizes Curriculares. Diretrizes gerais para o curso de Serviço Social. (Com base no currículo mínimo aprovado em Assembleia Geral Extraordinária de 08 de novembro de 1996). Rio de Janeiro, 1996.

BEHRING, Elaine. Brasil em contra-reforma: desestruturação do Estado e perda de direitos. 2 ed. São Paulo: Cortez, 2008.

BEHRING, Elaine. A política social no capitalismo tardio. São Paulo: Cortez, 2002.

BRAZ, M. Mudanças no perfil das lutas de classes e modismos conceituais e tormento de Sísifo das ciências sociais. In: BRAVO, M. I. S; MENEZES, J. S. B. de. (Orgs.). Saúde, serviço social, movimentos sociais e conselhos: desafios atuais. 2.ed. São Paulo: Cortez, 2012.

DRAIBE, S. M. As políticas sociais e o neoliberalismo. Revista USP (Dossiê Liberalismo/Neoliberalismo), São Paulo, n. 17, p. 96-101, mar./abr./maio, 1993.

DURIGUETTO, M. L. Sociedade civil e democracia: um debate necessário. São Paulo: Cortez, 2007.

FORTI, V.; COELHO, M. Contribuição à crítica do projeto-político do serviço social: considerações sobre fundamentos e cotidiano institucional. In: ; GUERRA, Y. A. D. (Orgs.). Projeto ético do serviço social: contribuições à sua crítica. Rio de Janeiro: Lumen Juris, 2015. p. 39-70.

GUERRA, Y. A. O estágio supervisionado como espaço de síntese da unidade dialética entre teoria e prática: o perfil do profissional em disputa. In: SANTOS, C. M. dos., LEWGOY, A. M. B., ABREU, M. H. E. (Orgs.). FORTI, V., GUERRA, Y. (Coord. da série). A supervisão de estágio em Serviço Social: aprendizados, processos e desafios. Coletânea nova de serviço social. Rio de Janeiro: Lumen Juris, 2016. p. 101-124.

GUERRA, Y. A. Sobre a possibilidade histórica do projeto ético político profissional: a apreciação crítica que se faz necessária. In: FORTI, Valéria L.; GUERRA, Yolanda A. D. (Orgs.). Projeto ético do serviço social: contribuições à sua crítica. Rio de Janeiro: Lumen Juris, 2015, p. 39-70. 


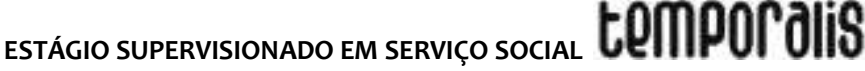

GUERRA, Y. A. D. Expressões do pragmatismo no Serviço Social: reflexões preliminares. R. Katál., Florianópolis, v. 16, n. esp., p. 39-49, 2013.

HARVEY, D. A Condição Pós-Moderna. 20. ed. São Paulo: Loyola, 2010.

IAMAMOTO, M. V. 80 anos do Serviço Social no Brasil: a certeza na frente, a história na mão. Serv. Soc. Soc., São Paulo, n. 128, p. 13-38, jan./abr. 2017.

IAMAMOTO, M. V. Serviço Social em tempo de capital fetiche: capital financeiro, trabalho e questão social. 2. ed. São Paulo: Cortez, 2008.

IAMAMOTO, M. V. O Serviço Social no Processo de Reprodução das Relações Sociais. In: IAMAMOTO, M. V.; CARVALHO, Raul de. Relações Sociais e Serviço Social no Brasil. 14. ed. São Paulo: Cortez, 2001, p. 71-12

MARX, Karl. Capítulo VI inédito do Capital: resultados do processo de produção imediata. São Paulo: Centauro, 2004.

NETTO, J. P. Uma face contemporânea da barbárie. Novos Rumos, Marília, v. 50, n. 1, 2013.

NETTO, J. P. Capitalismo Monopolista e Serviço Social. 8. ed. São Paulo: Cortez Editora, 2011.

NETTO, J. P. Ditadura e Serviço Social: uma análise do Serviço Social no Brasil pós-64. 12. ed. São Paulo: Cortez Editora, 2008.

NETTO, J. P. Notas sobre a reestruturação do Estado e a emergência de novas formas de participação da sociedade civil. In: BOSCHETTI, I. CÉSAR, M. A. CARVALHO, D. B. B. de. (Orgs.). Política Social: alternativas ao neoliberalismo. Brasília (DF): UNB, Programa de Pós-graduação em Política Social, Departamento de Serviço Social, 2004, p. 61-83.

NETTO, J. P. A construção do projeto ético-político do Serviço Social. In ABEPSS, CFESS. Capacitação em Serviço Social e Política Social. Módulo 1. Brasília, CEAD, 1999, p. 93-110.

NETTO, J. P. Transformações Societárias e Serviço Social: notas para uma análise prospectiva da profissão no Brasil. Serviço Social \& Sociedade, São Paulo, n. 50, 1996, p. 87-132.

RAICHELIS, R. O assistente social como trabalhador assalariado. Desafios frente a violação de seus direitos. Serv. Soc. Soc, São Paulo, n. 107, p. 420-437, jul./set. 2011.

RAMOS, S. R.; ABREU, M. H. E. Estratégias de enfrentamento e lutas do Serviço Social brasileiro frente a precarização da formação e do trabalho profissional e suas implicações no estágio supervisionado. In: SANTOS, C. M. dos.; LEWGOY, A. M. B.; ABREU, M. H. E. (Orgs.). FORTI, V.; GUERRA, Y. (Coord. da série). A supervisão de estágio em Serviço Social: aprendizados, processos e desafios. Coletânea nova de serviço social. Rio de Janeiro: Lumen Juris, 2016. p. 79-97. 
REIS, M. B. M. dos. Notas sobre o Projeto ético-Político da Profissão. In: CRESS/7a. Região. Assistente social: ética e direitos. Rio de Janeiro, CRESS/7a. Região, 2000. p. 405-419.

SANTOS, C. M. dos. Na prática a teoria é outra? Mitos e dilemas na relação entre e teoria, prática, instrumentos e técnicas no Serviço Social. Rio de Janeiro: Lumen Juris, 2010.

SILVA, M. O. da S. (Org.). O Serviço Social e o popular: resgate teórico-metodológico do projeto profissional de ruptura. São Paulo: Cortez, 2011.

\section{Mônica Freitas FERRI}

Graduada em Serviço Social e Mestre em Política Social pela UFES. Doutoranda do Programa de Pós Graduação em Serviço Social da UFRJ. Professora do Departamento de Ciências Humanas e Sociais da Universidade Federal dos Vales do Jequitinhonha e Mucuri (Campus do Mucuri). 